\title{
Development of Responsive Writing Ability: the Chance Virtual Instruction Creates
}

\author{
Gholam-Reza Abbasian, Atiyeh Zeinalian Bafandeh \\ Imam Ali and Islamic Azad (South Tehran Branch) Universities, Faculty of Persian Literature \& Foreign \\ Languages (IAU, South Tehran), Palestine Sq., Tehran, IR IRAN; Postal Code: 1416894351 \\ gabbasian@gmail.com \\ Islamic Azad University (South Tehran Branch), Faculty of Persian Literature \& Foreign Languages (IAU, \\ South Tehran), Palestine Sq., Tehran, IR IRAN; Postal Code: 1416894351
}

\begin{abstract}
The ability to write and respond in a formal manner is an important skill in different areas. It has been seen that learners have problem with how to write and/or to respond in a formal manner. Being a quasi-experimental study, this study investigated the opportunities virtual instruction creates for the development and assessment of English responsive writing ability. The underlying premise was that virtual instruction, i.e., e-learning, can assist foreign language learners in the development of their general responsive writing ability. However, the role of instructional setting could not be so easily overlooked. So, the purpose of the present study was to recognize if there is any difference between EFL and ESL learners' general responsive writing ability. In order to meet the objectives, 60 learners, divided into ESL and EFL groups, participated in this study. The ESL group consisted of 20 participants and 40 EFL learners were divided into two groups; one as the experimental group which received virtual instruction, while the other as the control group received class-based instruction. The study employed a process of exchanging emails in order to trace responsive writing ability development. Findings indicate that virtual instruction as far as the responsive writing ability was concerned, has an effective role in enhancing the learners' written responses. Furthermore, these findings also show that the learners of the two EFL and ESL experimental groups significantly outperformed the EFL Control group, though the EFL experimental group outperformed both ESL and control groups. The findings also indicate that the EFL learners' development depends on the researcher's responsive written feedback.
\end{abstract}

atiyehzeinalian@gmail.com

Keyword: Virtual Instruction; E-learning; Responsive writing.

\section{Council for Innovative Research}

Peer Review Research Publishing System

\section{Journal: Journal of Social Sciences Research}

Vol. 5, No. 3

Jssreditor.cir@gmail.com

www.jssronline.com

Page | 881

November 20, 2014 


\section{INTRODUCTION}

Nowadays, the ability to write has become an important skill in our literate world since many things need to be conveyed by writing. The ability to write and respond in a formal manner is an important skill in different areas. Brown (2004) categorized writing performance into four types including: imitative, intensive, responsive and extensive. It is commonly seen that language learners in general and EFL ones in particular have problems with various forms of formal writing and written performance types; they do not well know how to write and or respond in a formal manner. Regardless of performance types, writing development is a multi-faceted issues which should be approached from a number of measurement criteria. In this regard, Brown and Bailey (1984, as cited in Brown, 2004) designed an analytical scoring scale that specified five major categories including organization, logical development of ideas, grammar, punctuation and style. So, the learners' writings must be surveyed on each of the five subscales of writing separately, in order to understand on which subscale or subscales learners have more problem, too. However, integrating the investigation of writing skill as a unitary trait on one hand, and its categories and measures as its sub-components in a single study like this on the other may seem bulky. So the focus of this study revolves around investigating writing as a whole.

Another issue that can affect teaching and learning writing is the different environment that language acquisition takes place; ESL and EFL. According to the convention of using, EFL accounts for language learning that occurs when English is not the native language of a society, and ESL refers to language learning that takes place in a country where English is the main language spoken (Van Patten \& Lee, 1990). The distinction between ESL and EFL learners is useful in the argument about the product, in relation to both eventual proficiency, and the relative impact of certain influences, for example, first language influence (Bardovi-Harlig, 1995).

Moreover, today, online correspondence, especially in the form of e-mail and internet, is developing quickly as it reflects the competence and professionalism of the person involved in virtual instruction. These technological developments have greatly affected all areas of language education including teaching and testing writing skill. Virtual instruction has been found to encourage participation in writing activity. Given our recognition of the so-called mystique of e-mail, the empirical testimony for using e-mailing to enhance the responsive writing and writing ability is scarce, and may perhaps be nonexistent among Iranian EFL speaking community. Even in other environments, only a few studies have been conducted delving into the impact of the virtual instruction and the uncovered promises that it may have for writers in English. The purpose of the present study is then to look for empirical testimony for the most important role of e-mailing in development of English responsive writing and writing ability. Hence, more elaborate and controlled investigations should be performed into the effects of e-mailing on the development of EFL and ESL learners' general responsive writing ability.

\subsection{Types of Writing}

There are four categories regarding four types of writing performance proposed by Brown (2004) which are imitative, intensive, responsive and extensive. Imitative: At this stage, form is the primary concern to assess learner's skills in the fundamental and basic tasks of writing letters, words, punctuation, and very brief sentences. This category also includes the ability to spell correctly and to perceive phoneme-grapheme correspondences in the English spelling system. Intensive: This refers to producing appropriate vocabulary within a context, collocations and idioms, and correct grammatical features up to the length of a sentence. Responsive: Assessment tasks require learners to perform at a limited discourse level. They are asked to connect sentences into a paragraph and create a logically connected sequence of two or three paragraphs. Form-focused attention is mostly at the discourse level and its emphasis is on context and meaning. Extensive: Extensive writing is a major research project report, or even a thesis which implies successful management of all the processes and strategies of writing for all purposes. Writers emphasize on achieving a purpose, organizing and developing ideas logically, using details to support or illustrate ideas, demonstrating syntactic and lexical variety, and in many cases, engaging in the process of multiple drafts to achieve a final product.

Writing could be the most difficult skill to teach among the four skills of listening, speaking, reading, and writing, since writing produces concrete records that allow numerous drafts of revision and consist of both technical accuracy and artistic fluency (Kashiwagi, 2007). According to the most writing teachers and researchers $s$ in the area of second or foreign language, teacher feedback is, as identified here by responsive writing which associates mutual and give and take process, most effective when it is provided during the intermediate stages of the writing process (Ferris, 2003a). When students make subsequent revisions during this process they can respond to teacher feedback (Zamel, 1982). Ferris (1995) conducted a study on the effects of a multiple-draft composition setting on student reactions to teacher feedback. Based on the results of her study, the students reread their papers more often, paid more attention to the teacher's feedback on the earlier drafts than on the final drafts, paid attention more on the teacher's comments on grammar than on the other aspects, and felt that the teacher's feedback had helped them to improve their writing. In another study, Jerram, Glynn and Tuck (1988) carried out a study on responsive written feedback in which teachers responded to students' writing with personal written responses, as opposed to corrective error feedback. The study concluded that the students wrote more in their responses and their writing was more interesting and imaginative. In another study the efficacy of focused written corrective feedback was examined by Bitchener's (2008). The study employed three types of written direct corrective feedback and a no-feedback treatment and focused on the use indefinite article "a" and definite article "the". Focusing on the issue of accuracy, the study revealed that the students in the groups receiving written focused corrective feedback outperformed those who did not receive any feedback. There is evidence that the explicitness of written feedback may play a role in the success of student revision (Goldstein, 2006). She notes that, when teacher feedback lacks clarity, students may not attempt to make revision or, when they revise, they may revise it unsuccessfully. Conrad and Goldstein (1999) also found that students often had difficulty to react to comments that did not explicitly state that a 
revision was needed. As a result, students either did not attempt to revise their text or, if they did, they revised it unsuccessfully.

Furthermore, giving feedback to or responding a writer can be carried out in various forms as there are various types and forms of feedback reported and investigated in the literature. However, in light of the technological developments, virtual instruction is getting a promising welcome and popularity as a proper modality of interaction, even when writing skill is concerted.

\subsection{Virtual instruction}

Virtual instruction has been found to encourage participation in writing activity. A reason for it is that e-mail and online chats provide a non-threatening atmosphere in which writers feel less self-conscious about expressing themselves, encouraging even shy students who usually refuse to speak in face-to-face discussions to actively participate in online chats (Kupelian, 2001). Gonzalez and Perez (2001) found that second-language learners using e-mail for their dialogue journals produced more language than those who used pencil and paper. A comparison in second language learning was made by Wang (1993) in the discourse of ESL students' dialogue journals written in both e-mail and traditional paper format. She concluded that the students using e-mail journals wrote greater amounts of text, asked more questions, and used different language functions more frequently than did students writing on paper. Evidence from prior research suggests that this environment supports active and collaborative learning and the construction of knowledge (Killins, 2002). It has also been confirmed in Chiu's study (2005) that e-mail communication can lead to better classroom interactions and creative learning. This can also improve students' confidence and provide less difficult writing skills in classrooms. It will be willing to accept that e-mail technology can positively help students bridge the gap between "skillgetting and skill-using", borrowing the expression from Rivers (1975, p. 12).

Given the trend of the discussion put forth so far, this study was an attempt to: first and foremost, address the extent of the effectiveness of virtual instruction (i.e., e-learning and e-teaching) of responsive writing skill distinctively in EFL and ESL contexts compared with conventional class-based instruction. So hypothetical differences between EFL and ESL participants and e-learning vs. class-based instructions of responsive general writing ability of both groups in both settings shaped the core of the efforts made in this research. Much more specifically the study focused on the following major question addressed through three minor ones:

1. Is e-learning more effective than class-based instruction in developing intermediate EFL and ESL learners' general responsive writing ability distinctively?

- Is there any significant difference between the EFL and ESL learners' general responsive writing ability?

- Is there any significant difference between the control group (exposed to class-based instruction) and ESL learners' general responsive writing ability?

- Is there any significant difference between the control group (exposed to class-based instruction) and EFL learners' general responsive writing ability?

\section{METHOD}

\subsection{Participants}

To accomplish the objectives of this study, 60 learners, male and female, participated in this study. These 60 participants were divided into 3 groups. Two groups of Iranian adult (pre-university level) male learners at the intermediate level of English proficiency, studying at third grade of High School as the EFL Control group and EFL experimental group were selected. Each group consisted of 20 participants. They have been studying English at private English language institutes too. ESL experimental group consisted of 20 (i.e., 18 Indian and 2 Pakistani) adult male/female learners (aged 18-19) at the intermediate level of English proficiency.

To obtain the population required for the EFL experimental and Control groups, a version of the Preliminary English Test (PET) was administered and 40 students from 4 different classes were randomly chosen based on their standing position on the normal distribution curve and the Standard Deviation measure. The ESL participants were selected from among those English learners who have been living in a country where English is the first or the official language of the country and the non-native speakers have to learn English as their second language. So a general background questionnaire was given to about 52 people that among them 20 participants considered enjoying higher command and proficiency level were selected.

\subsection{Instrumentation and Materials}

Three specific types of instruments along with a number of writing pieces and samples developed throughout the experiment by the participants were used to collect data for the purpose of the study. First, as it was stated, the PET was used for sampling purpose. Then, the participants produced two various, though roughly similar, business letter prior to and after the experiment in order to compare their entry and exit behaviors. Their first writing was considered as the writing pretest. It was, however, used not only as a diagnostic test but as a platform for the initiation of the treatment. The letters on the first specified topic were read and their contents were modified by giving necessary feedback according to the responsive writing characteristics that were listed by Brown (2004) and the letter writing format suggested by Ashley (2010) and Bly (2004); the two last sources were used as the bases for the instructional materials, of course. Similarly, 
the final piece of their writing was used as an achievement test. It enjoyed similar characteristics as those followed in the pre-test except giving back any further feedback.

\subsection{Procedure}

The whole process of treatment went around letter exchanges between the researchers and the participants. There were around six topics chosen from Oxford Handbook of Commercial Correspondence by A. Ashley (2010) and Webster's New World Letter Writing Handbook by Robert W. Bly (2004). Both experimental groups along with the control group received the instructions on responsive writing for seven sessions. The experimental groups received the instructions via e-writing through e-mail exchanges, while the control group was taught conventionally in the classroom setting. None of the groups did receive any explicit instruction, rather the instructions were given implicitly through the explicit feedbacks that researchers gave on each letter of the participants [hope explicit feedback cannot be equated and taken as synonymous to explicit instruction]. The feedbacks were given according to the responsive writing characteristics.

At the beginning of the treatment process a topic was sent via e-mail to the participants of the EFL and ESL groups asking them to write a letter and send it back to the researchers. Any guidance or further explanations were given via e-mail. After they wrote the letters on the specified topic and sent it back, the researchers s read their letters and modified the letters' content according to the responsive writing characteristics that were listed by Brown (2004) and modified their letters' format according to the characteristics of that specific type of letter mentioned in Ashley's and Bly's books. These modifications were in the form of feedbacks that the researchers gave on their writings. After giving the necessary feedbacks, the researchers sent the e-mail back to the participants so that they could see the feedbacks and understand on which parts they had weaknesses and should make modifications on their subsequent letters.

Along with the e-mail on the first topic, another e-mail which contained the new topic was also sent to the participants. This process went on consecutively till six topics were written in such a cycle of writing and feedback. Every change in the format and styles of each participant's writings were observed and recorded. ESL and EFL learners' writings to these formal e-mails were compared in terms of the aspects of responsive writing so that in the course of letter exchanges both the trend of developments could be recorded and measured.

The participants of the control group were provided with the same six topics given to the EFL and ESL groups as well. Each topic was given to the participants in the classroom and they were asked to write the related letter conventionally on a paper and bring it next session. The same letters were collected in the following session; the researchers read them and gave necessary feedbacks on each. For this group too, the instruction was in the form of feedback. Every session the letters were given back to the participants so they could see the feedbacks and modify progressively their own writings accordingly. The letters again were collected by the researchers in order to document them and do further analyses on them. Any changes in their styles and format of writing were observed and recorded. The next topic was given to the participants and they were asked to bring the letter next session, and this process went on up to $6^{\text {th }}$ topic.

\subsection{Scoring}

At the end of the letter writing process, the collected letters from all the three groups were rated by two raters. The score was done based on both analytic and holistic analyses for rating tasks provided by Brown and Bailey, but since the categories if writing are not the concern of this very study, so only the results of the holistic scoring are reported. To enhance the reliability and consistency in scoring, two raters were involved in this process

\section{RESULTS}

\subsection{Pretest of general responsive writing}

A one-way ANOVA was run to compare the means of the EFL, ESL and Control group on the pretest of writing in order to prove that they enjoyed the same level of writing ability prior to the main study. It should be mentioned that the three groups enjoyed homogenous variances on the pretest of writing. As displayed in Table 1 the Levene's F-value of 1.73 does not show any significant differences $(F=1.73, P<.05)$ in variances, indicating that they enjoyed homogeneous variances on the pre-test of writing.

Table 1. Levene's Test of Homogeneity of Variances; Pretest of Writing

\begin{tabular}{|c|c|c|c|}
\hline Levene Statistic & $\mathrm{df1}$ & $\mathrm{df2}$ & Sig. \\
\hline 1.732 & 2 & 57 & .186 \\
\hline
\end{tabular}


Moreover, based on the results displayed in Table $2\left(F(2,57)=1.02, P>.05 ; \omega^{2}=.001\right.$ which represents a weak effect size), it can be concluded that there were not any significant differences between means of the EFL, ESL and Control group on the pretest of writing. Thus, it can be additionally claimed that they enjoyed the same level of writing ability prior to the main study.

Table 2. One-Way ANOVA Pretest of Writing by Groups

\begin{tabular}{|c|c|c|c|c|c|}
\hline & Sum of Squares & Df & Mean Square & $\mathrm{F}$ & Sig. \\
\hline Between Groups & 1.051 & 2 & .525 & 1.021 & .367 \\
\hline Within Groups & 29.319 & 57 & .514 & & \\
\hline Total & 30.370 & 59 & & & \\
\hline
\end{tabular}

As displayed in Table 3 means of the EFL, ESL and Control groups on the pretest of writing test are 13.99, 14.29 and 14.25 , respectively.

Table 3. Descriptive Statistics Pretest of Writing by Groups

\begin{tabular}{lllllll}
\hline & $\mathrm{N}$ & Mean & Std. Deviation & Std. Error & \multicolumn{2}{l}{$95 \%$ Confidence Interval for Mean } \\
\cline { 5 - 7 } & & & & & Lower Bound & Upper Bound \\
\hline ESL & 20 & 13.99 & .855 & .191 & 13.59 & 14.39 \\
\hline EFL & 20 & 14.29 & .687 & .154 & 13.97 & 14.61 \\
\hline Control & 20 & 14.25 & .584 & .131 & 13.98 & 14.52 \\
\hline Total & 60 & 14.18 & .717 & .093 & 13.99 & 14.36 \\
\hline
\end{tabular}

The figure 1 is, in fact, an illustrative display and support of all the statistics reported in the above tables, displaying nonsignificant differences among the participants prior to the experiment.

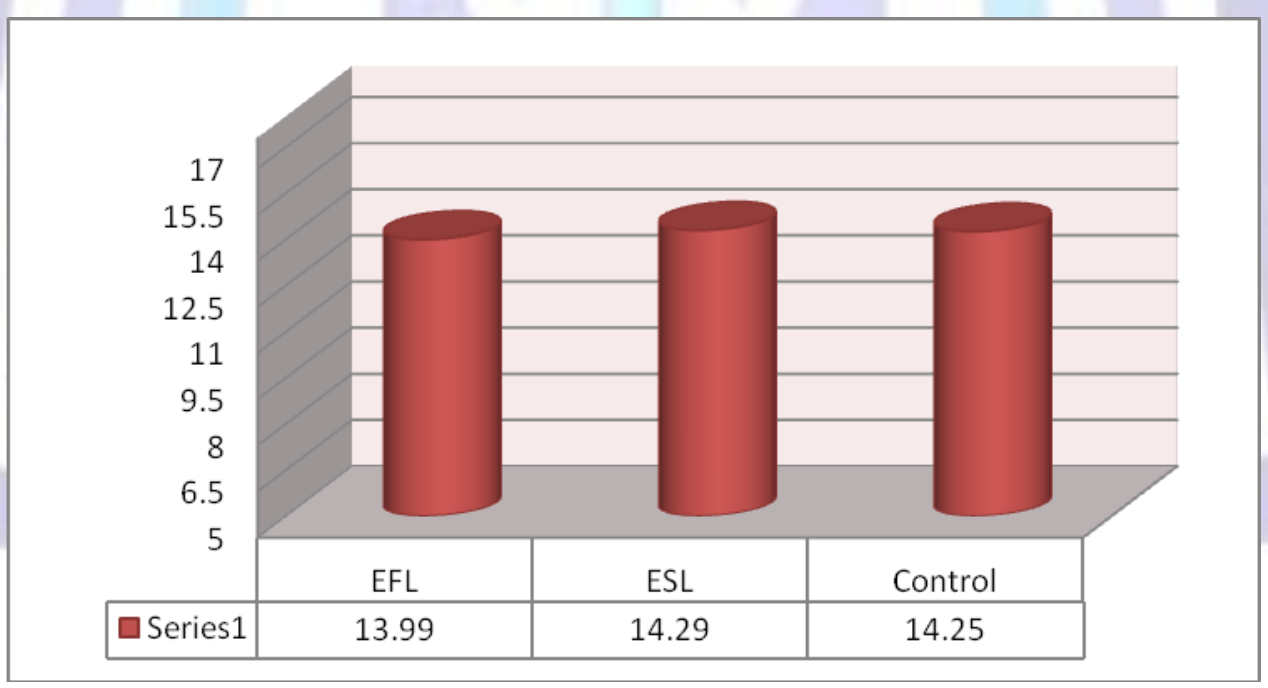

Figure 1. Pretest of writing by groups

\subsection{Investigation of the Research Questions}

Having analyzed the data in terms of meeting the assumptions of normality and homogeneity of the variances, the researchers employed parametric paradigm in order to investigate the research questions. The details are as follows:

\subsubsection{Addressing the Major and Minor Research Questions}

The major research question which concentrated on whether 'e-learning is more effective than class-based instruction in developing intermediate EFL and ESL learners' general responsive writing ability distinctively' , along with the pertinent sub-questions, was addressed statistically. To do so, a one-way ANOVA was run to compare the means of the EFL, ESL and Control groups on the posttest of writing in order to compare the effects of e-learning and class-based instruction on the development of the EFL and ESL learners' general responsive writing ability. It should be mentioned that the three 
groups enjoyed homogenous variances on the posttest of writing. As displayed in Table 4, the Levene's F-value of 2.07 is not significant $(\mathrm{F}=2.07, \mathrm{P}<.05)$. The statistics are summarized in Table 4.

Table 4. Levene's Test of Homogeneity of Variances; Posttest of Writing

\begin{tabular}{|c|c|c|c|}
\hline Levene Statistic & df1 & df2 & Sig. \\
\hline 2.077 & 2 & 57 & .135 \\
\hline
\end{tabular}

Based on the results displayed in Table $5\left(F(2,57)=73.66, P<.05 ; \omega^{2}=.70\right.$ which represents a large effect size $)$, it can be concluded that there were significant differences between means of the EFL, ESL and Control groups on the posttest of writing. Thus, it can be claimed that the first major null-hypothesis as e-learning is not more effective than class-based instruction in developing EFL and ESL learners' general responsive writing ability distinctively is rejected.

Table 5. One-Way ANOVA Posttest of Writing by Groups

\begin{tabular}{|c|c|c|c|c|c|}
\hline & Sum of Squares & Df & Mean Square & F & Sig. \\
\hline Between Groups & 117.309 & 2 & 58.655 & 73.662 & .000 \\
\hline Within Groups & 45.387 & 57 & .796 & & \\
\hline Total & 162.696 & 59 & & & \\
\hline
\end{tabular}

As displayed in Table 6, means of the EFL, ESL and Control group on the posttest of writing test are 18.98, 17.95 and 15.64, respectively.

Table 6. Descriptive Statistics Posttest of Writing by Groups

\begin{tabular}{ccccccc}
\hline & $\mathrm{N}$ & Mean & Std. Deviation & Std. Error & \multicolumn{2}{c}{ 95\% Confidence Interval for Mean } \\
\cline { 3 - 6 } & & & & & Lower Bound & Upper Bound \\
\hline ESL & 20 & 18.98 & .951 & .213 & 18.53 & 19.43 \\
\hline EFL & 20 & 17.95 & .716 & .160 & 17.61 & 18.28 \\
\hline Control & 20 & 15.64 & .986 & .220 & 15.17 & 16.10 \\
\hline Total & 60 & 17.52 & 1.661 & .214 & 17.09 & 17.95 \\
\hline
\end{tabular}

Although the F-value of 73.66 (Table 5) indicates significant differences between the mean scores of the three groups on the posttest of writing, the post-hoc Scheffe's tests should be run to compare the groups two by two in order to probe the minor research hypotheses associated with the first major research question. Based on the results displayed in Table 7 it can be concluded that:

A: The EFL learners $(M=18.98)$ significantly outperformed the ESL subjects $(M=17.92)$ on the posttest of writing ( $M D=$ $1.03, \mathrm{P}<.05)$. Thus, the first minor null-hypothesis as there is not any significant difference between the EFL and ESL learners' general responsive writing ability is rejected.

B: The ESL learners $(M=17.92)$ significantly outperformed the control group $(M=15.64)$ on the posttest of writing (MD = $2.31, \mathrm{P}<.05)$. Thus, the second minor null-hypothesis as there is not any significant difference between the control group and ESL learners' general responsive writing ability is rejected.

Table 7. Post-Hoc Scheffe's Tests Posttest of Writing by Groups

\begin{tabular}{|c|c|c|c|c|c|c|}
\hline \multirow{2}{*}{ (I) Group } & \multirow{2}{*}{ (J) Group } & \multirow{2}{*}{$\begin{array}{c}\text { Mean Difference } \\
(\mathrm{I}-\mathrm{J})\end{array}$} & \multirow{2}{*}{ Std. Error } & \multirow{2}{*}{ Sig. } & \multicolumn{2}{|c|}{ 95\% Confidence Interval } \\
\hline & & & & & Lower Bound & Upper Bound \\
\hline \multirow{2}{*}{ ESL } & EFL & 1.035 & .282 & .002 & .33 & 1.74 \\
\hline & Control & 3.345 & .282 & .000 & 2.64 & 4.05 \\
\hline EFL & Control & $2.310^{*}$ & .282 & .000 & 1.60 & 3.02 \\
\hline
\end{tabular}


C: The EFL learners $(M=18.98)$ significantly outperformed the control group $(M=15.64)$ on the posttest of writing (MD = $3.34, \mathrm{P}<.05)$. Thus, the third minor null-hypothesis as there is not any significant difference between the control group and EFL learners' general responsive writing ability is rejected.

\section{DISCUSSION}

The results of the analyses revealed that there were significant differences among the means of all groups on the posttest of writing. Thus, it can be claimed that e-learning is more effective than class-based instruction in developing EFL and ESL learners' general responsive writing ability distinctively. This finding is consistent with the study done by Chiu (2005) confirming that email communication, when pedagogically employed, can lead to better classroom interactions and creative learning. This can also improve and build up students' confidence and facilitate their writing skills in literacy classrooms. Also, evidently, it is claimed that e-mail technology as a kind of Computer Mediated Communication (CMC) can positively help students bridge the gap between "skill-getting and skill-using", borrowing the expression from Rivers (1975, p. 12). This finding is consistent with the study done by Smith (1999), in which he found that, upon comparing two writing instruction methods - one computer-mediated and the other traditional, "the computer users improved significantly in their ability to read and express oral and written ideas" (pp. 80-81). Incorporating the use of e-mail and reporting findings on its efficacy as a medium for developing responsive writing ability has been an effective part of the instructional design tested in this study. The findings are compatible with the established findings favoring the use of email as a medium and technique for developing writing skills (e.g. D'Souza, 1992, Anderson \& Lee, 1995; Romiszowski \& de Haas, 1989).

This study tried to provide feedback on students writing as a kind of indirect or implicit instruction. On the way of teaching writing to the English learners several studies have been carried out to examine the effects of multiple-draft revisions and the teacher's feedbacks on students' writing. Hedgcock and Lefkowitz (1994) surveyed on students' perception of helpfulness of teachers' comments regarding their writing, including grammatical accuracy. According to the results of their study, students preferred teachers' feedback on grammatical errors. Students also preferred that teacher feedback with grammatical correction be given on both students' first and final drafts. Also as this study used written feedback with explicit comment, there is evidence that the explicitness of written feedback may play a role in the success of student revision (Goldstein, 2006). Conrad and Goldstein (1999) in their study found that students often had difficulty to react to comments that did not explicitly state that a revision was necessary. So, students either did not attempt to revise their text or, if they did, they revised it unsuccessfully. Ferris and Roberts (2001) in their study involving 72 university ESL students found that the clarity of teacher written feedback and the nature of errors to be corrected in students' text helped students in revising their texts successfully. In summary, the studies discussed above show that providing teacher feedback with explicit corrective comments was more advantageous than their implicit or no corrective feedback.

\section{CONCLUSION}

Conclusions extracted from this study confirm previously established research findings. Given the authentic learning setting in which this study took place, the results are promising for educators interested in effective virtual instruction and Internet-Based Instruction (IBI) and the related models, as the one in this study which used emailing, especially when integrated with emailing and communicative learning. Attitudes towards learning English can be enhanced in environments such as virtual instruction and IBI, especially when the results of the different studies are promising for a better future of English learning and teaching. It can be said that e-learning is more effective than class-based instruction in developing EFL and ESL learners' general responsive writing, since EFL group outperformed the ESL and control group in all steps of 
research. Also, as a whole, EFL and ESL groups both outperformed the control group in all steps of research process. Such an outperformance by the EFL and ESL groups can be attributed to the differences in instructional settings. The EFL and ESL groups received instruction through virtual instruction but the Control group exposed to class-based instruction. The in-class setting is likely to expose learners to affective filters (i.e., test anxiety, motivation, or fear of negative evaluation), influencing writing results negatively (Lybeck, 2002).

On the other hand, written data associated with the virtual instruction are likely to be obtained under a less stressful learning environment. Examining the students' written data obtained from email exchanges proved the effectiveness of implicit instruction through the virtual instruction channel (i.e. email exchanges). Comparing the data obtained from both, in-class and virtual instruction channel settings, this study found improvement in the learners' responsive writing ability of the groups which received instruction through virtual instruction and email exchanges. As it has also been confirmed in Chiu's study (2005) pedagogically employing communication through email can lead to better classroom interactions and creative learning. This can also improve and build up students' confidence and facilitate their writing skills in classroom.

Based on the findings the authors seize the opportunity to invite interested researchers to contribute to further relevant explorations in this field; more specifically in investigating other types of communicative writing such as imitative, intensive (controlled) and extensive writing as already ignited by Brown (2004) and evoked the motive behind this study. Moreover, focus on formal and informal styles that learners use in their writings seems intact in this field. Last but at least equally important is the necessity of incorporating other modalities of language, e.g., speaking skill since it was found that written data associated with communication is likely to be obtained under a less stressful learning environment.

\section{REFERENCES}

[1] Anderson, J. \& Lee. A. (1995). Literacy teachers learning a new literacy. A study of the use of mail in a reading education class, Reading Research and instruction, 34, 222-238.

[2] Ashley, A. (2010) Oxford handbook of commercial correspondence. Oxford University Press.

[3] Bardovi-Harlig, K. (1995). The interaction of pedagogy and natural sequences in the acquisition of tense and aspect. In F. R. Eckman, D. Highland, P. W. Lee, J. Mileham, \& R. Rutkowski Weber (Eds.), Second language acquisition theory and pedagogy (pp. 151-168). Mahwah, NJ: Lawrence Erlbaum Associates.

[4] Bitchener, J. (2008). Evidence in support of written corrective feedback. Journal of Second Language Writing, 17, 102-118.

[5] Bly W., Robert, (2004) Webster's New World Letter Writing Handbook. Wiley Publishing, Inc.

[6] Brown, H. D. (2004). Language assessment--principles and classroom practices. NY: Pearson Education, Inc.

[7] Chiu, C. (2005). Writing in English: Perspectives of an ethnic Chinese teacher and her students. PhD Thesis, The University of New Mexico, AAT 3177082.

[8] Conrad, S. M., \& Goldstein, L. M. (1999). ESL student revision after teacher-written comments: Text, contexts, and individuals. Journal of Second Language Writing, 8(2), 147-179.

[9] D'Souza, P. (1992). mail in academic settings: A multipurpose communications tool. Educational Technology, $32,22-$ 25.

[10] Ferris, D. R. (1995). Student reactions to teacher response in multiple-draft composition

[11] classrooms. TESOL Quarterly, 29(1), 35-53.

[12] Ferris, D. R. (2003a). Response to student writing: Implications for second language students. Mahwah, NJ: Lawrence Erlbaum Associates, Inc.

[13] Ferris, D. R., \& Roberts, B. (2001). Error feedback in L2 writing classes: How explicit does it need to be? Journal of Second Language Writing, 10, 161-184.

[14] Goldstein, L. (2006). Feedback and revision in second language writing: Contextual, teacher, and student variable. In K. Hyland \& F. Hyland (Eds.), Feedback in second language writing: Context and issues (pp. 185-205). Cambridge, UK: Cambridge University Press.

[15] Gonzalez, B. M. \& Perez, L. C. (2001, March). " mail in foreign language learning revisited". Paper presented at the Annual Meeting of Teachers of English to Speakers of Other Languages, St. Louis, MO. [ED 458 817]

[16] Hedgcock, J., \& Lefkowitz, N. (1994). Feedback on feedback: Assessing learner receptivity to teacher response in L2 composing. Journal of Second Language Writing, 3(2), 141-163.

[17] Jerram, H., Glynn, T., \& Tuck, B. (1988). Responding to the message: Providing a social context for children learning to write. Educational Psychology, 8(1\&2), 31-40.

[18] Kashiwagi, T. (2007). Kakukoto no sidou. [Instruction of writing]. In Higuchi, A. \& Shimatani, H (Ed.), 21 seiki no eigokakyouiku. [English education in the $21^{\text {st }}$ century]. (pp. 133-147). Tokyo: Kairyuudo. 
[19] Killins, J. (2002). Educators collaborating across cultures in a computermediated communications environment. Unpublished Ed.D. Dissertation: Ontario Institute for studies in Education, University of Toronto, Canada.

[20] Kupelian, M. (2001). The use of e-mail in the L2 classroom: An overview. "Second Language Learning \& Teaching", 1. Retrieved on December 15, 2003, from http://www.usq.edu.au/opacs/cllt/sllt/1-1/Kupelian01.htm Leibowitz, W. R. (1999).

[21] Lybeck, K. E. (2002). The role of acculturation and social networks in the acquisition of second language pronunciation. Unpublished doctoral dissertation. University of Minnesota.

[22] Romiszowski. A. J. \& de Haas. J. A. (1989). Computer mediated communication for instruction: Using e-mail as a seminar. Educational Technology. 29. 7-14.

[23] Rivers, W. (1975). Teaching Foreign Language Skills. 2nd edition. Chicago: UCP.

[24] Smith, H. (1999). Opportunities for information and communication technology in the primary school. Stoke on Trent: Trentham Books Limited.

[25] Wang, Y. M. (1993). E-mail dialogue journaling in an ESL reading and writing classroom. Unpublished Ph.D. dissertation, University of Oregon at Eugene.

[26] Zamel, V. (1982). Writing: The process of discovering meaning. TESOL Quarterly, 16(2), 195-209.

\section{Authors' biographies with photos}

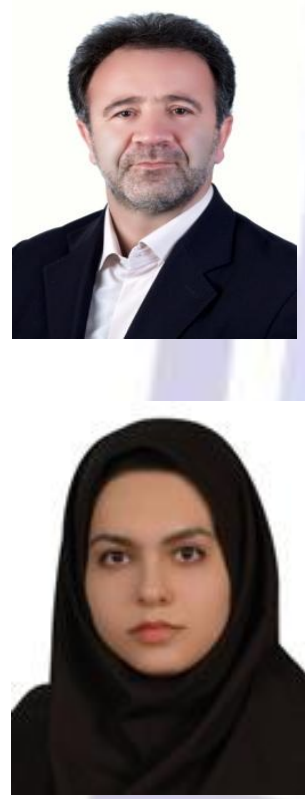

Dr. Gholam-Reza Abbasian, an assistant professor of TEFL at Imam Ali University \& IAU (South Tehran Branch), has presented at (inter) national conferences, authored and translated about 15 books, and published a good number of scholarly articles. He offers mainly Psycholinguistics, Language Testing and Syllabus Design courses. He has received awards as top scholar and the most successful teacher for almost seven consecutive years. He is the internal manager of JOMM, reviewer of FLA and GJER journals and a member of the editorial board of JSSIR.

Atiyeh Zeinalian Bafandeh, has a B.A. in English Literature from Khayyam University of Mashhad and an M.A. in TEFL from Islamic Azad University (South Tehran Branch). She has more than six years of professional teaching experience at public and private English institutions for both adults and children. 